University of Nebraska - Lincoln

DigitalCommons@University of Nebraska - Lincoln

2011

\title{
Executive control and dimensions of problem behaviors in preschool children
}

\author{
Kimberly A. Espy \\ University of Nebraska-Lincoln, kespy2@unl.edu \\ Tiffany Sheffield \\ University of Nebraska-Lincoln, tsheffield2@unl.edu \\ Sandra A. Wiebe \\ University of Alberta, sandra.wiebe@ualberta.ca \\ Caron A. C. Clark \\ University of Oregon, caron.clark@unl.edu \\ Matthew J. Moehr \\ University Wisconsin-Madison
}

Follow this and additional works at: https://digitalcommons.unl.edu/dcnlfacpub

Espy, Kimberly A.; Sheffield, Tiffany; Wiebe, Sandra A.; Clark, Caron A. C.; and Moehr, Matthew J., "Executive control and dimensions of problem behaviors in preschool children" (2011). Developmental Cognitive Neuroscience Laboratory - Faculty and Staff Publications. 51.

https://digitalcommons.unl.edu/dcnlfacpub/51

This Article is brought to you for free and open access by the Developmental Cognitive Neuroscience Laboratory at DigitalCommons@University of Nebraska - Lincoln. It has been accepted for inclusion in Developmental Cognitive Neuroscience Laboratory - Faculty and Staff Publications by an authorized administrator of DigitalCommons@University of Nebraska - Lincoln. 


\title{
Executive control and dimensions of problem behaviors in preschool children
}

\author{
Kimberly Andrews Espy, ${ }^{1}$ Tiffany D. Sheffield, ${ }^{1}$ Sandra A. Wiebe, ${ }^{1}$ \\ Caron A.C. Clark, ${ }^{1}$ and Matthew J. Moehr ${ }^{2}$ \\ 1. University of Nebraska-Lincoln, Lincoln, NE, USA \\ 2. University Wisconsin-Madison, Madison, WI, USA \\ Corresponding author - Kimberly Andrews Espy, University of Nebraska-Lincoln; email kespy2@unl.edu
}

\begin{abstract}
Background: Despite the widespread recognition of the importance of executive control (EC) in externalizing psychopathology, the relation between EC and problem behavior has not been well characterized, particularly in typically developing preschoolers.

Method: Using the sample, battery of laboratory tasks, and latent variable modeling methods described in Wiebe, Espy, and Charak (2008), systematic latent dimensions of parent-rated problem behavior, measured by integrating scales from developmental and clinical traditions, were determined empirically, and then were related to EC.

Results: Substantial relations between EC and problem behaviors were revealed by extracting the common variance of interest and eliminating extraneous variance, which were robust to estimated child intelligence and differed somewhat in preschool boys and girls. Conclusion: Preschool EC measured by laboratory tasks appears to tap abilities that strongly and robustly support broad control processes enabling behavioral regulation across cognitive and emotional domains.
\end{abstract}

Keywords: Executive function, pre-school children, behavior problems, disruptive behavior, psychometrics, ADD/ADHD

The central goal of the field of developmental psychopathology is to delineate early developmental pathways to later problem behaviors associated with substantial impairment for the child and burden for caregivers and society more generally (e.g., Campbell, 1982; Lahey et al., 2004). Recently developed diagnostic tools (e.g., Keenan et al., 2007; Wakschlag et al., 2007) make it increasingly possible to identify maladaptive behaviors early in development (Egger, Kondo, \& Angold, 2006; Wakschlag, Leventhal, Pine, Pickett, \& Carter, 2006). The preschool years mark the transition from infancy to elementary school age, in which children increasingly can modulate their behavior appropriately in contexts in and outside of the home (Espy, 2004). These capacities are supported by the protracted development of prefrontal systems (Benes, 2001; Giedd et al., 1999; Huttenlocher, 1990) and unique substantive gains in prefrontal system connectivity (Thatcher, 1991). Thus, the preschool period is a particularly important developmental period for the emergence of executive control (EC).

There is consensus that executive processes play a key role in developmental pathways towards dysfunctional outcomes (Nigg \& Casey, 2005; Spira \& Fischel, 2005) and in externalizing child psychopathology (e.g., Barkley, 1997; Castellanos, Sonuga-Barke, Milham, \& Tannock, 2006; Willcutt, Doyle, Nigg, Faraone, \& Pennington, 2005), as children with attention deficit-hyperactivity disorder (ADHD) typically show deficits on tasks that demand executive processes (e.g., Sonuga-Barke, 2005;
Berwid et al., 2005; Martinussen, Hayden, Hogg-Johnson, \& Tannock, 2005), as do many children with aggressive conduct and defiance problems (Oosterlaan, Logan, \& Sergeant, 1998; Séguin, Nagin, \& Assaad, 2004). However, specifying the relation between early EC and outcome has proven challenging, in part due to variation in disciplinary traditions of assessment of executive processes, regulatory behaviors, and symptomatology. Numerous terms have been used to describe these processes (Bell \& Deater-Deckard, 2007), for example, 'executive/attention/emotion/cognitive/inhibitory/effortful control,'executive function,' and 'self regulation.' The degree of overlap among these concepts is unclear. Here, we utilize the term 'executive control' to refer to the higher-order, top-down abilities that enable the execution of an action requiring the active maintenance of information in light of competition, delay, distraction, or interference under changing contingencies. With its traditional roots in neuropsychology, EC typically is measured using individually administered tasks in the laboratory, and this also reflects the level of analysis used here.

In contrast, regulatory behaviors often include additional emotionally laden or affectively charged elements, and typically have been assessed via parent or teacher ratings on age-appropriate scales, for example, those designed to assess child temperament (e.g., Child Behavior Questionnaire; Rothbart, Ahadi, Hersey, \& Fisher, 2001; although see Kochanska, Murray, \& Coy, 1997, for an example of direct observational methods). 
Identification of symptomatology expressly focuses on maladaptive behaviors and, like regulatory behavior, includes a focus on emotionally charged behaviors, and is measured most often by clinically oriented symptom checklists completed by the parent. On symptomatology questionnaires, however, parents endorse how much a given behavior is problematic. Regulatory behavior questionnaires are designed to assess the full range of individual differences, rather than to identify maladaptive behaviors per se, but children with sufficiently persistent and pervasive behavior problems will likely elicit extreme ratings on temperament items (e.g., rating of 7/extremely true on the item 'Gets mad when even mildly criticized'). The methodological intersection and conceptual overlap between measurement of regulatory behavior in the normative developmental literature and symptomatology in the child psychopathology literature is not clear, particularly in young children. Although there are theoretical questions of how temperament and psychopathology are related (e.g., Nigg, Goldsmith, \& Sachek, 2004; Martel, 2009), from a measurement perspective, there is considerable overlap in item/scale content as well as a common reliance on parent ratings of child behavior relative to internal normative expectations, and empirically, the respective scale scores are correlated (e.g., Eisenberg et al., 2001). Therefore, we integrate the normative regulatory and symptomatology approaches under a broader rubric of problem behaviors that the child demonstrates in real-world settings to capture the full spectrum of individual differences in behavioral outcome, as evaluated by a key informant, the parent, in this critical period.

Despite differences in terminology and measurement, progress identifying links between emergent executive processes and selected domains/aspects of early problem behavior has been made. For instance, a number of existing studies with preschoolers have reported correlations between performance on laboratory-based measures of inhibitory control and ratings on DSM-based checklists for ADHD/ODD (oppositional defiant disorder) (bivariate $r$ s typically in the .2 to .3 range; Brocki, Nyberg, Thorell, \& Bohlin, 2007; Raaijmakers et al., 2008; Sonuga-Barke, Dalen, \& Remington, 2003; Thorell \& Wåhlstedt, 2006; Youngwirth, Harvey, Gates, Hashim, \& Friedman-Weieneth, 2007). These associations are generally robust after controlling for IQ and conduct problems (Raaijmakers et al., 2008; Sonuga-Barke et al., 2003). More broadly, Hughes and colleagues (Hughes, Dunn, \& White, 1998; Hughes, White, Sharpen, \& Dunn, 2000) have demonstrated that preschool children identified as 'hard-to-manage' using the Strengths and Difficulties Questionnaire (Goodman, 1997) perform poorly on measures of working memory, inhibitory control, planning and set-shifting relative to age-matched peers. Studies by this group and others also demonstrate moderate associations between a variety of performance measures of EC and observational ratings of aggressive, antisocial behavior (Bierman, Nix, Greenberg, Blair, \& Domitrovich, 2008; Dunn \& Hughes, 2001; Hughes et al., 2000). Children at risk for ADHD or conduct difficulties were oversampled in the above-referenced studies, raising questions of generalizability for typically developing samples. In addition, the relations between EC and conduct difficulties often are not significant after controlling for symptoms of ADHD (e.g., Brocki, Nyberg, Thorell, and Bohlin, 2007; Sonuga-Barke, Dalen, Daley, \& Remington, 2002; Thorell \& Wåhlstedt, 2006; although see Raaijmakers et al., 2008, for an exception), raising further questions as to the specificity of relations between EC and various aspects of problem behavior. Nonetheless, there is some evidence that laboratory-administered measures of control processes may be associated with more nuanced variations in behavior, including the modulation of anger and fear (Blair, 2003; Eisenberg et al., 2009; Kochanska, Murray, \& Harlan, 2000). Furthermore, spatial conflict task performance in typically developing preschoolers has been related to poorer parent-rated regulatory behavior (Chang \& Burns, 2005; Gerardi-Caulton, 2000; Rothbart, Ellis, Rueda, \& Posner, 2003).

While these various studies have concentrated on discrete clinical, neuropsychological or temperament outcomes, they collectively suggest that EC may be linked to one or more critical behavioral components that underpin a wide spectrum of difficulties. In keeping with a recent emphasis on the multifaceted, dimensional nature of problem behavior (Snowling, 2009; Martel, 2009), this study's first aim was to map the underlying structure of problem behavior derived from the integration of normative regulatory and symptomatology measures. Not only is this multi-measure approach methodologically more robust than a reliance on single outcome measures, but it might provide a finer-grained characterization of problem behavior and 'widen the net' for capturing those young children who may not ordinarily be identified using typical diagnostic measures. For instance, there is a well-known difficulty in detecting the inattentive subtype of ADHD in preschoolers (e.g., Lavigne et al., 1998a, 1998b; Landau, Milich, \& Widiger, 1991). Most psychiatric symptomatology measures have relied on items querying 'distractibility' to capture problems appropriately directing and sustaining attention. Although this distractibility conceptualization may work well in school-aged children (as most older children are not distractible, it is straightforward for parents to detect and rate behavioral deviations), such items are unlikely to discriminate well in preschoolers. In young children, problems with distractibility and variable task persistence, for example, are difficult to disentangle from normative behaviors, such as the drive for exploration and social interaction (Ruff \& Rothbart, 1996). Essentially, parents of preschoolers have difficulty seeing the 'signal' of attention problems amidst 
the 'noise' of preschool distractibility. By drawing on both clinically and developmentally oriented scales, our aim was to enhance developmental specificity and better capture these more difficult-to-distinguish problem behaviors in this unique period.

Our second goal was to characterize the relations between the identified underlying dimensions of problem behavior and EC. Critically, extant studies that have examined the EC:problem behavior relation have been limited by their reliance on relatively few measures of EC, where the poor or ill-defined psychometric properties of single preschool EC measures likely obscure any true associations with behavioral outcomes (Willcutt et al., 2005). Similarly, because of its higher-order, top-down nature, EC modulates other, more modular processes (e.g., language, visuospatial skills), and thus by definition, executive task performance includes surplus variability related to these other processes that can spuriously impact observed correlations, particularly as these modular skills also develop during the preschool period. Using a battery of executive tasks and simply summing respective scores to yield a single executive composite, Hughes and Ensor (2008) found a significant relation $(\beta=-.17)$ between executive skills at age 3 and problem behaviors (also defined by a single, summed composite) at age 4. Structural equation modeling can be used to empirically quantify the shared, common variance across a large battery of executive tasks, to 'isolate' the executive from other non-executive demands, thereby providing a more reliable and powerful measure of EC. Wiebe et al. (2008) utilized these methods to compare the fit of several a priori theoretically derived 1-, 2- and 3-factor models based on differing executive demands, as well as 'control' models parsed on non-executive demands of verbal, spatial or speeded response requirements. Because the unitary model described the latent structure in the least number of paths and fit the obtained data as well as more complex models, it was retained as the preferred model (Bollen, 1989). Although many models of EC have focused on the characterization of its constituent components, the results of Wiebe et al. (2009) are in keeping with increasing evidence for a more unitary structure in early childhood (Carlson, 2005; Hughes \& Ensor, 2008) and have been independently replicated in different samples with different measures of EC (Wiebe et al., 2009; Hughes, Ensor, Wilson, \& Graham, 2010). This unitary model is also broadly consistent with systems neuroscience conceptualizations (e.g., Miller \& Cohen, 2001; Knight, 2007), where EC is more than just a collection of functions localized in discrete cortical areas, but rather, the fundamental role of the prefrontal system is modulatory, exerting ongoing top-down control by biasing activity in task-relevant neural pathways compared to those carrying competing 'bottom-up' information (e.g., distractors) represented in other neural areas (Buschman \& Miller, 2007), against a moment-to-mo- ment backdrop of internal state. Indeed, even in studies that have utilized confirmatory factor analysis to identify latent components that might underpin EC in older children and adults, the correlations among the identified latents have been moderate to high (ranging from .30 to .75), suggesting an underlying unity in these processes even in older age groups (Friedman et al., 2007; Lehto, Juujarvi, Kooistra, \& Pulkkinen, 2003; Miyake et al., 2000; Huizinga, Dolan, \& van der Molan, 2006; van der Sluis, de Jong, \& van de Leij, 2007). Finally, this simpler, unitary structure of EC in early childhood also is consistent with theoretical and empirical evidence for a greater diffusivity both of cognitive skills and neural patterns of activation in early childhood (Karmiloff-Smith, 2007). Younger children, for example, show greater local (as opposed to longer distance) neural connectivity (Thatcher, 1997; Fair et al., 2008), and greater diffusion in activation patterns (Casey, 2000), less specialization of neural circuits and less modularity of functional processes (e.g., Bell \& Fox, 1992; Durston \& Casey, 2006). Given the recent and limited evidence to support the identified latent unitary structure of EC in preschoolers, the relation of EC to dimensions of problem behavior is unknown.

Finally, as many studies in this area have utilized high-risk samples that are predominantly male (e.g., Brocki et al., 2007; Hughes \& Ensor, 2008), there has been limited analysis of sex differences in the relation between EC and preschool problem behavior, with those studies that have examined this issue reporting contradictory findings (Berlin, Bohlin, \& Rydell, 2003; SonugaBarke et al., 2003; Thorell \& Wåhlstedt, 2006). In Berlin et al. (2003), for example, laboratory-measured inhibition skills were related to inattentive/hyperactive symptoms more strongly in boys compared to girls, and the association for girls was evident only in the school setting. In contrast, Sonuga-Barke et al. (2003) reported comparable relations between performance on EC measures and reported symptoms of ADHD/CD (conduct disorder) in girls and boys. Clear sex-related discrepancies in reported rates of externalizing behavior (Karreman, van Tuijl, van Aken, \& Dekovic, 2009; Olson, Sameroff, Kerr, Lopez, \& Wellman, 2005) and executive proficiency (Wiebe et al., 2008), as well as differences in cerebral maturation (Mahone \& Wodka, 2008), underscore the need to address this issue. More importantly, studies to date have operated under the implicit assumption that EC measures capture the same latent constructs in girls and boys, an assumption that clearly requires explicit empirical evaluation if sex differences in the relation to problem behavior are to be interpreted reliably.

Against this background, structural equation modeling was used to empirically a) define the dimensions of problem behavior in preschoolers, $b$ ) determine the relation of EC to these problem dimensions, and c) characterize sex differences in the EC:problem behavior relations. 
Table 1. Summary of executive control tasks and dependent measures

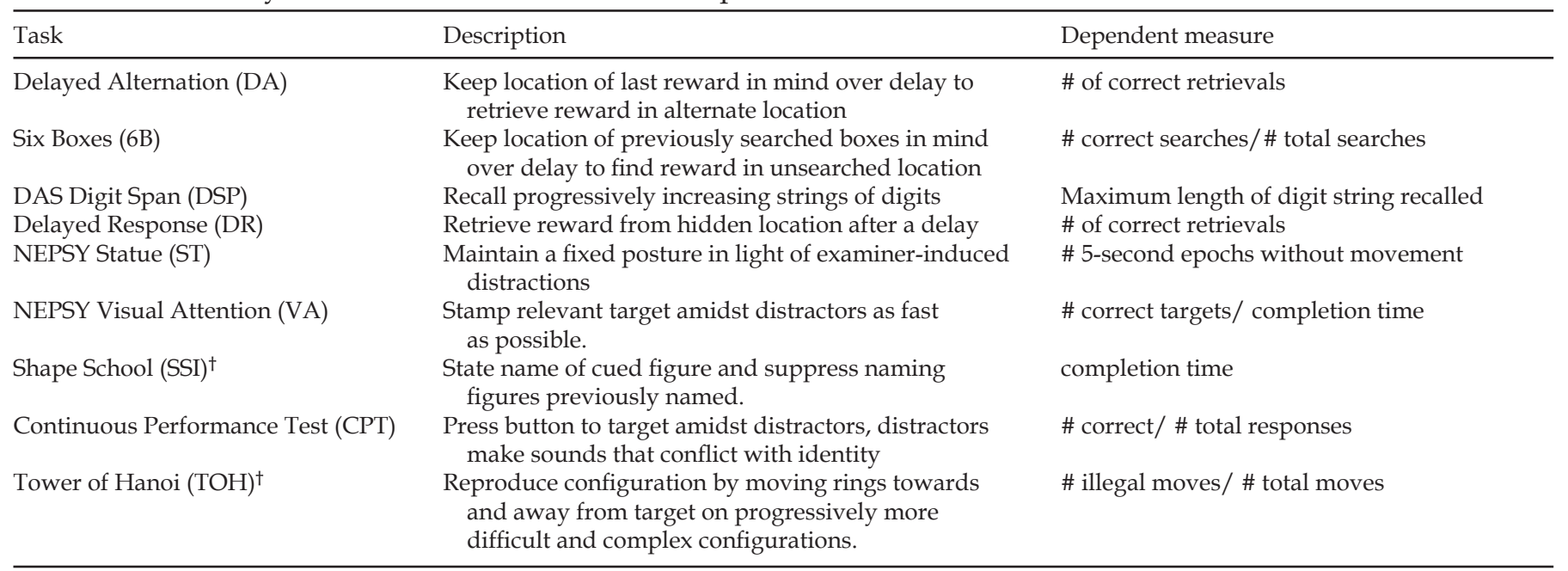

${ }^{\dagger}$ Measure was reflected for CFA and SEM analyses to ease factor loading interpretations.

In comparison to other studies that typically have used single indicators of either EC or problem behavior, we hypothesized that these latent variable methods would reveal strong relations between EC and problem behavior when empirically defined by the common variance shared across measures, even in a non-referred community sample where such relations typically can be attenuated relative those that include diagnosed children.

\section{Method}

\section{Participants}

The sample described in more detail in Wiebe et al. (2008) was used here, and included 243 preschool children (135 girls, 108 boys). Participants were recruited through birth announcements, local preschools, the health department, and by word of mouth. Children ranged in age from 29 to 72 months $(M=47$ months, $S D=12$ months), and included 171 Caucasian, 43 African American, 9 Asian American, 1 Native American, 4 Hispanic, and 14 multi-racial children (1 not reported). The sample was typically developing, with a mean estimated general intelligence score of $101(S D=13)$ on the Peabody Picture Vocabulary Test - III (PPVT-III), Receptive (Dunn \& Dunn, 1997). Mean maternal education of the sample was 14 years $(S D=2.25$ years $)$.

\section{Procedure}

In a single session, the participating children completed a battery of EC measures, which varied in format and executive demands (e.g., maintaining information, resisting distraction, resolving conflict, and flexibly shifting). Trained graduate students administered and scored all child assessments, and the child's parent (typically the mother) was in the room throughout testing. Table 1 includes a summary of each EC task and the resultant de- pendent measure. Briefly, in Delayed Alternation (Espy et al., 1999; Goldman, Rosvold, Vest, \& Galkin, 1971), a treat was hidden out of the child's sight in one of two locations. The correct location alternated whenever the child correctly retrieved the reward, so the child had to remember the previous reward location across a 10-second delay. For Six Boxes (Diamond et al., 1997), 6 boxes differing in shape and color were baited initially, and the child was allowed to open one box on each trial. Box locations were scrambled between trials, so children had to remember which boxes had been opened already. Children also completed the Digit Span subtest of the Differential Abilities Scale (Elliott, 1990). Delayed Response (Goldman, Rosvold, \& Mishkin, 1970) involved treats that were hidden in a pseudo-random order in two locations in the child's view. After a 10-second delay with active distraction, the child was allowed to search at one of the locations. Two NEPSY (Korkman, Kirk, \& Kemp, 1998) subtests were used. In Statue, children stood in a statue pose for 75 seconds while the examiner coughed, dropped her pencil, and so on to distract the child. Each 5-second epoch was scored for eye and body movement, and talking. In Visual Attention, children were asked to circle the target cats amidst a variety of distractors. In the Shape School Inhibit Condition (Espy, 1997; Espy, Bull, Martin, \& Stroup, 2006), children were required to name the colors of different shape characters when cued with a happy face, and suppress the naming response when characters had sad faces. For Tower of Hanoi (TOH; Simon, 1975; Welsh et al., 1991), children were required to move a set of rings into a goal configuration by moving one ring at a time and following rules about relative placement of the rings (Bull, Espy, \& Senn, 2004). Finally, in the Child Continuous Performance Test (CPT; Kerns \& Rondeau, 1998), children pressed a button when pictures of infrequent target animals were displayed on a computer screen and did not respond to frequent distracter pictures, where animals made sounds that conflicted with their identity. In 
Wiebe et al. (2008) a series of structural models were fit to characterize the latent structure of preschool EC, and the preferred, unitary model was used here.

To measure problem behavior, questionnaires were completed by the parent while the child participated in the laboratory evaluation. Because the goal was to determine the relation between EC and problem behavior across the broad continuum, both clinically and developmentally oriented questionnaires were utilized: the Child Behavior Checklist (CBCL; Achenbach \& Rescorla, 2000), the Behavior Rating Inventory of Executive Function-Preschool Version (BRIEF-P; Gioia et al., 2003), and the Children's Behavior Questionnaire (CBQ; Rothbart et al., 2001). The well-known and validated ADHD and ODD scales from the CBCL were used, as well as all the scales from the BRIEF-P, another clinical questionnaire with demonstrated psychometric reliability and validity (Isquith, Gioia, \& Espy, 2004). The CBQ Inhibitory Control, Impulsivity, Activity Level, Attentional Focusing and Anger/Frustration scales (reliability $=.71-.83$; Rothbart et al., 2001) were used. Both the CBCL and BRIEF-P utilize a 3-point problem-oriented symptom scale for parents to rate their child's behavior, whereas on the CBQ, a 7-point, individual difference-type scale is used.

\section{Statistical methods}

Statistical analyses were conducted using SAS 9.2 for descriptive analyses and Mplus 5.1 (Muthén \& Muthén, 2006) for all other analyses. Mplus uses maximum likelihood estimation to fit models to the observed means and covariances using the EM algorithm to handle missing data (Muthén \& Muthén, 2006). Some measures were reflected (multiplying the estimate by -1) to simplify interpretation by enabling directional consistency, such that higher values for EC tasks indicated better performance and higher values for questionnaire data indicated more reported problem behavior.

To address the goal of determining how preschool EC relates to problem behavior, the single-factor, unitary latent structure from the individually administered, laboratory tasks already identified in Wiebe et al. (2008) was used to model EC. Descriptive statistics and correlations among the executive measures are found in Wiebe et al.
(2008) and descriptive statistics and correlations with the problem behavior indicators are included in Table 2 .

The next step was to determine the best-fitting structure of the outcome, problem behavior. Latent variables were constructed from the 11 CBCL, BRIEF-P, CBQ subscales that were expected to index the problem behavior constructs of interest. Descriptive statistics and correlations for these indicators are presented in Table 2. Of note are the significant, moderate correlations among the behavior scales that indicated good measurement coherence in this preschool age range. Confirmatory factor analysis was used to compare the fit of four alternative latent problem behavior factor structures manifested by the 11 subscales, shown in Figure 1. First, a unitary model, where all scale indicators loaded on a single latent, was fit that evaluated whether a single externalizing construct best represented the communality across scales. This structure is consistent, for example, with the higherorder factor structure of the CBCL scales (Achenbach \& Rescorla, 2000). A 2-factor solution then was evaluated, where those problem behaviors pertaining to regulating cognition versus emotion were parsed (e.g., Carlson \& Wang, 2007; Leerkes, Paradise, O'Brien, Calkins, \& Lange, 2008; Nigg \& Huang-Pollock, 2003). Then in the 3 -factor model, cognition dysregulatory behavior was differentiated further into those behaviors that pertained to problems appropriately directing and sustaining attention contrasted to those that reflect disinhibited behaviors based on the traditional DSM-IV diagnostic distinction. A 4-factor model was fit, where the hyperactive behaviors were parsed from those reflecting disinhibition (e.g., Kieling, Goncalves, Tannock, \& Castellanos, 2008). Finally, the retained, best-fitting model was compared to a 'control' model where the respective scales were modeled to load by original scale purpose, that is, the two psychopathology scales (CBCL ADHD and ODD) were constrained to load on one factor, the CBQ scales on a second factor, and the BRIEF-P scales on a third. ${ }^{1}$ This control model tests whether psychopathology, temperament, and 'dysexecutive' constructs, as originally conceived, better describe the latent structure of the obtained data compared to the problem behavior dimension model. All structural equation models were conducted regressing child age (in months) as a covariate to statistically control for

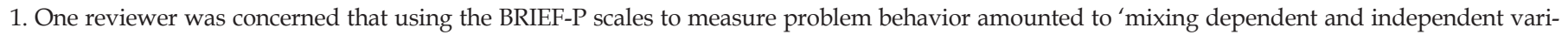
ables.' The purpose of our analytic approach is specifically to empirically test differing latent measurement configurations among scales that all share the same common method and purpose - a parent rating their child's externalizing behavior as they see it expressed in their everyday interactions and experiences with the child compared to expectations of a like child of the same age. While clinicians may attach any particular label to a content-coherent scale, fundamentally what is asked of the parent rater is the same on the CBCL, CBQ, and BRIEF-P scales - to make judgments about their child's problem behavior relative to their internal expectations. Furthermore, substantial correlations were observed between scales (in Table 2), and there is substantial overlap in item content across these instruments (e.g., items from the CBCL include 'Can't sit still, restless or hyperactive' and 'Angry moods,' those from the CBQ include 'Moves about actively when playing in the house' and 'Has temper tantrums when he/ she doesn't get what they want,' while items from the BRIEF-P include 'Is fidgety, restless or squirmy' and 'Mood changes frequently'). Thus, we empirically evaluated whether scale distinctions parsed by instrument type resulted in a tenable latent structure (in Table 3, 'Control' model). At least in this community sample, this model fit poorly, and in fact, the path from EC to the BRIEF-P latent path was the smallest in magnitude. Although distinctions of parent ratings on the BRIEF-P and their ratings of dysregulated, externalizing behaviors on the CBCL and CBQ were not supported, we nonetheless ran analyses that omitted the BRIEF-P scales to address this concern. Not surprisingly, three factors (the Attention Problems factor was not uniquely identified) best fit the data, where the relations between EC and the three behavior constructs were significant and similar in magnitude and pattern to the reported here. These results are available from the first author on request. 
Table 2. Descriptive statistics and correlations for problem behavior indicators and executive control tasks

\begin{tabular}{|c|c|c|c|c|c|c|c|c|c|c|c|c|c|c|}
\hline Measure & $N$ & $M S$ & $s D$ & 1 & 2 & 3 & 4 & 5 & 6 & 7 & 8 & 9 & 10 & 11 \\
\hline 2. BRIEF-P Working Memory (WM) & 225 & 1.59 & .33 & .68 * & - & & & & & & & & & \\
\hline 3. BRIEF-P Plan/Organize (PO) & 225 & 1.72 & .35 & $.56 *$ & .75 * & - & & & & & & & & \\
\hline $\begin{array}{l}\text { 5. CBCL Attention Deficit/Hyper- } \\
\text { activity Problems (ADHD) }\end{array}$ & 194 & .7 & .44 & $.69 *$ & .58 * & $.48 *$ & .47 * & - & & & & & & \\
\hline $\begin{array}{l}\text { 6. CBCL Oppositional Defiant } \\
\text { Problems (ODD) }\end{array}$ & 194 & .55 & .4 & $.54 *$ & .42 * & .37 * & $.58 *$ & $.65 *$ & - & & & & & \\
\hline 8. CBQ Impulsivity (IM) & 234 & 4.42 & .47 & .47 * & $.40 *$ & $.35 *$ & .15 * & $.50 *$ & $.37 *$ & .40 * & - & & & \\
\hline 9. CBQ Activity Level (AL) & 234 & 4.17 & .47 & $.50 *$ & .40 * & .36 * & .20 * & $.59 *$ & $.48 *$ & $.43 *$ & $.66^{*}$ & - & & \\
\hline 10. CBQ Attentional Focusing (AT) ${ }^{\dagger}$ & 234 & 4.44 & .54 & $.42 *$ & .56 * & .40 * & .23 * & .48 * & .29 * & $.52 *$ & .38 * & .34 * & - & \\
\hline 11. CBQ Anger/Frustration (AN) & 234 & 4.39 & .58 & .31 * & $.32 *$ & .34 * & $.44 *$ & $.48^{*}$ & $.47 *$ & $.36^{*}$ & .28 * & $.32 *$ & .25 * & - \\
\hline Delayed Alternation (DA) & 224 & 9.06 & 2.39 & -.03 & -.17 * & -.11 & -.07 & -.10 & -.12 & $-.12 \dagger$ & -.04 & -.05 & -.13 * & $-.12 \dagger$ \\
\hline Six Boxes $(6 \mathrm{~B})$ & 237 & .68 & .18 & .05 & -.06 & .00 & .05 & -.03 & -.02 & -.05 & -.07 & -.07 & -.09 & -.08 \\
\hline Continuous Performance Test (CPT) & 147 & .49 & .33 & -.14 & $-.21 *$ & -.03 & -.05 & -.08 & $-.17^{\dagger}$ & -.05 & $-.20 *$ & -.10 & $-.14 \dagger$ & .00 \\
\hline Tower of Hanoi $(\mathrm{TOH})^{\dagger}$ & 188 & .31 & .24 & -.01 & -.06 & .05 & .15 * & -.08 & $-.17 *$ & -.06 & -.10 & -.06 & -.11 & -.04 \\
\hline
\end{tabular}

${ }^{*} p<.05 ; \wedge p<.10 ;{ }^{\dagger}$ Measure was reflected for CFA and SEM analyses to ease factor loading interpretations.

age effects. Because all of the problem behavior structural equation models were nested, relative fit of these models was determined by first examining the $x^{2}$ difference, where a significant difference indicated that the more complex model fit the data better than the alternative. The $\chi^{2}$ statistic was not interpreted directly (Jöreskog, 1969) because 1) the goal was not testing a given hypothesis but rather one of fitting models with different numbers of parameters and deciding the best-fitting model, and 2) the $\chi^{2}$ statistic can be problematic due to sensitivity to sample size and missingness; non-significant values indicate good fit but become more difficult to obtain as the sample size increases. Other fit statistics were examined, where RMSEA (<.06) and CFI (>.95) indicate good fit (Hu \& Bentler, 1999; $\mathrm{Yu}, 2002)$, and a difference of more than 10 in BIC indicates better fit for the model with the lower value (Raftery, 1993). After selection of a final model, modification indices were examined to determine whether any correlated error terms should be added to improve model specification. Only those modifications that were justified theoretically (e.g., allowing correlated errors between scales on the same metric) were considered. Structural equation modeling was used to evaluate the EC:problem behavior relation by fitting paths between the unitary EC latent and the empirically derived problem behavior latents. By covarying the child's PPVTIII with EC, the robustness of the relations was examined in light of the child's estimated general intellectual abilities. Finally, sex effects were examined using invariance testing. A critical a of .05 was used for all statistical tests.

\section{Results}

Table 3 shows the fit indices of the 1-, 2-, 3- and 4-fac- tor models, as well as the control model. The 1-factor model fit the observed correlations poorly $\left(x^{2}=321\right.$, $\mathrm{df}=54, p<.001)$. A 2-factor model parsing the "emotional" vs. "cognitive" problem behavior dimensions was a significant improvement over the 1-factor model, but still did not fit the obtained data well. The 3-factor model also fit better than the 2-factor model, but again fit statistics indicated inadequate fit. The 4-factor solution with "Hyperactive Behaviors," "Disinhibition Behaviors," "Attention Problems," and "Emotion Dysregulatory Behaviors" constructs fit the observed data better than the 3-factor model and showed substantive improvement in the $\chi^{2}$ statistic, although the RMSEA and CFI were higher than preferred (Hu \& Bentler, 1999; $\mathrm{Yu}, 2002)$. Therefore, any modification indices above 10.00 were examined, which indicated unexplained covariance between $C B Q$ Attentional Focusing with CBQ Inhibitory Control, CBCL Oppositional Defiant Problems with CBCL Attention Deficit/ Hyperactivity Problems, and Brief-P Inhibit with Brief-P Emotional Control scales. Given that these scales have shared method variance, correlated errors for these scales were allowed. Modification indices also indicated unexplained covariance between the BRIEF-P Inhibit and CBQ Anger/ Frustration scales, consistent with results of Isquith, Gioia, and Espy (2004). Allowing correlated errors between the seven scales resulted in significant improvement in the $\chi^{2}$ and CFI statistics, and BIC reduction, although the RMSEA remained marginally higher than preferred. This 4-factor model with the correlated errors was retained as the best fitting, adequately capturing the underlying dimensions of preschool problem behavior. This 4-factor model also fit the obtained data substantially better than the control model. 
(a)

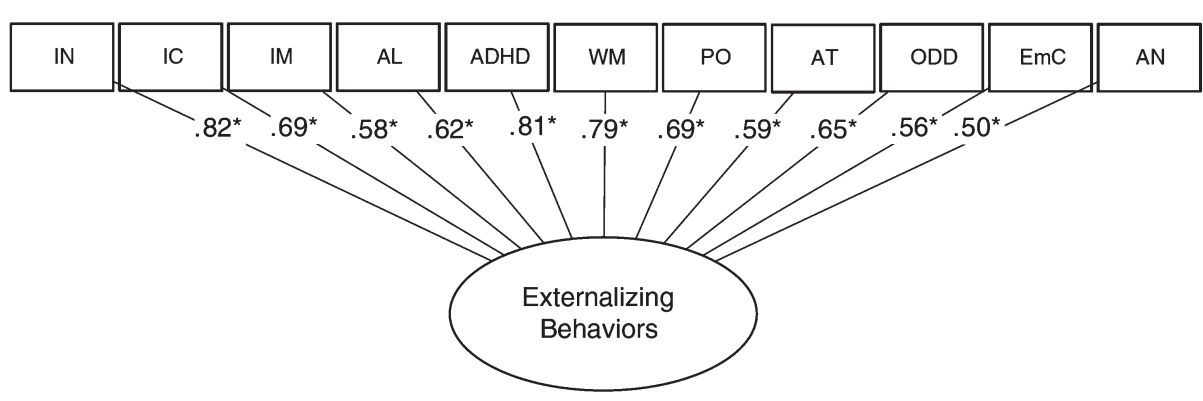

(b)

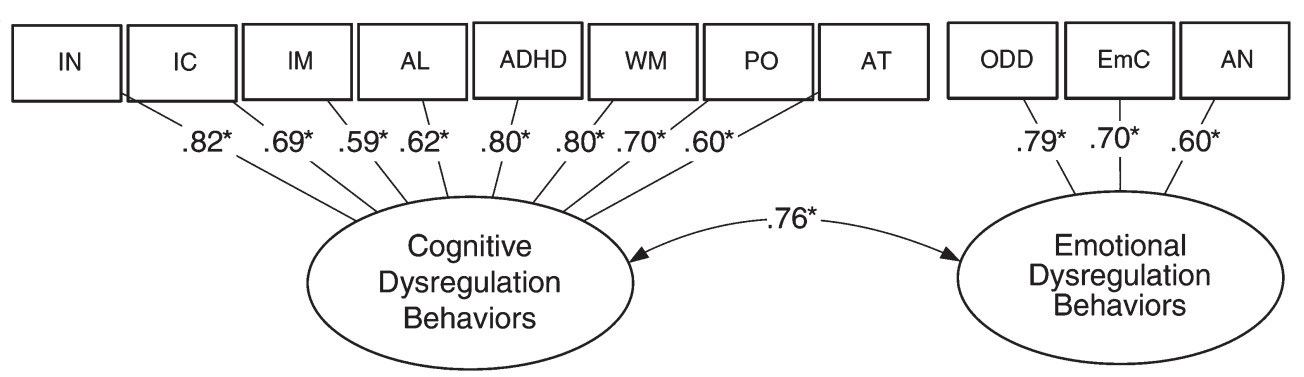

(c)
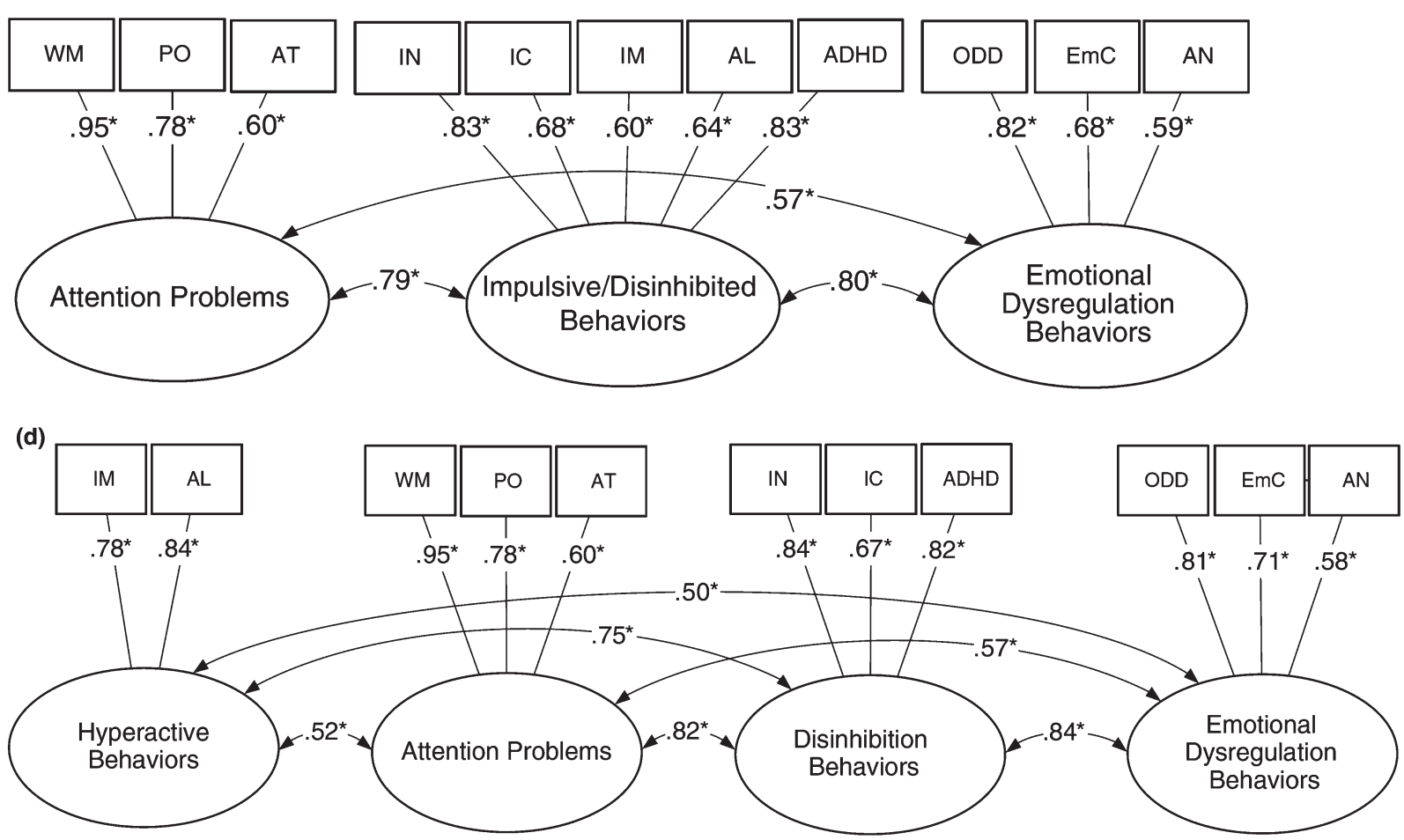

Figure 1. Alternative problem behavior structures. Standardized factor loadings are given for each indicator. IM = CBQ Impulsivity; $\mathrm{AL}=\mathrm{CBQ}$ Activity Level; $\mathrm{WM}=\mathrm{BRIEF-P}$ Working Memory; PO = BRIEF-P Plan/Organize; AT = CBQ Attentional Focusing; IN = BRIEF-P Inhibit; IC = CBQ Inhibitory Control; ADHD = CBCL Attention Deficit/Hyperactivity Problems; ODD = CBCL Oppositional Defiant Problems; EmC = BRIEF-P Emotional Control; AN = CBQ Anger/Frustration

The paths between latent EC and latent Hyperactive Behaviors, Attention Problems, and Disinhibition Behaviors (Figure 2) differed from zero and were substantial in magnitude ( $\lambda$ s ranged from -.42 to -.55 ). A child who scored 1 standard deviation lower than the mean in latent $\mathrm{EC}$, on average, was rated by their parent to show .42 SD more Hyperactive Behaviors, .55 SD more Atten- tion Problems, and .48 SD more Disinhibition Behaviors. The latent EC-Emotional Dysregulation Behaviors path was moderate $(\lambda=-.22)$ in magnitude, but not significant. The effect of the age covariate on latent preschool EC was large, $\beta=.85$, reaffirming the substantial agerelated differences in children's EC across the preschool period. Interestingly, age also was related positively 


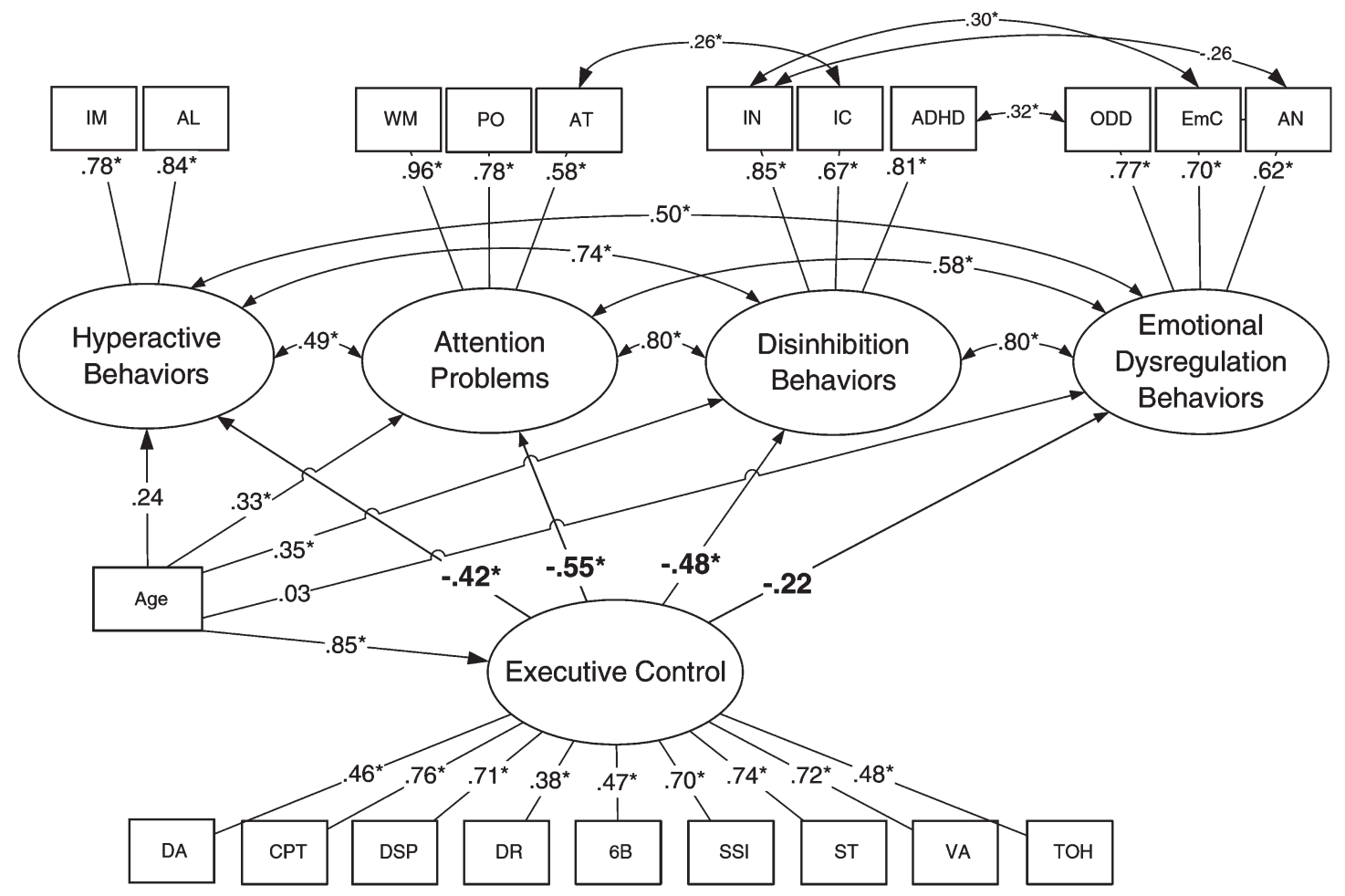

Figure 2. Problem behavior-executive control model. Standardized factor loadings and coefficients are reported. IM = CBQ Impulsivity; $\mathrm{AL}=\mathrm{CBQ}$ Activity Level; WM = BRIEF-P Working Memory; PO = BRIEF-P Plan/Organize; AT = CBQ Attentional Focusing; IN = BRIEF-P Inhibit; IC = CBQ Inhibitory Control; ADHD = CBCL Attention Deficit/Hyperactivity Problems; ODD = CBCL Oppositional Defiant Problems; EmC = BRIEF-P Emotional Control; AN = CBQ Anger/Frustration; DA = Delayed Alternation; $\mathrm{CPT}=$ Continuous Performance Test; DSP = DAS Digit Span; DR = Delayed Response; 6B = Six Boxes; SSI = Shape School Inhibit condition; ST = NEPSY Statue; VA = NEPSY Visual Attention; TOH = Tower of Hanoi

Table 3. Goodness of fit indices for alternative problem behavior structures and for executive control-problem behavior model

\begin{tabular}{lrrrrrl}
\hline Model & $\Delta \chi^{2}$ & $\Delta \mathrm{df}$ & $p$ & RMSEA & CFI & \multicolumn{1}{l}{ BIC } \\
\hline 1-factor & - & - & - & .076 & .787 & 5278.93 \\
2-factor & 39 & 2 & $<.001$ & .068 & .817 & 5250.65 \\
3-factor & 73 & 3 & $<.001$ & .063 & .873 & 5193.67 \\
4-factor & 70 & 4 & $<.001$ & .093 & .926 & 5145.36 \\
Final 4-factor* & 50 & 4 & $<.001$ & .069 & .963 & 5116.80 \\
Control Model & - & - & - & .136 & .852 & 3362.38 \\
EC-Problem & - & - & - & .042 & .960 & 9774.66 \\
Behavior & & & & & & \\
\hline
\end{tabular}

* With correlated errors allowed between 3 scales.

to the Attention Problems and Disinhibition Behaviors latents, indicating that parents endorse more problem behaviors of these types in older preschool children. When the child's estimated intelligence was included as a covariate $(\mathrm{CFI}=.957$; RMSEA $=.042$; BIC $=11591)$, the magnitudes of the relations between the EC and Problem Behavior latents were larger by .04 to .10; ranging from -.33, a marginal trend for the EC:Emotional Dysregulation path, to the significant -.46 for EC:Hyperactive Behaviors, -.55 for EC:Disinhibition Behaviors, and -.65 for EC:Attention Problems paths. Of note is the substantial magnitude of the EC:Problem Be- havior latent paths evident when using these structural equation methods.

Finally, invariance testing was used to evaluate potential measurement and structural differences in the final model between boys and girls. This final sex invariance model is shown in Figure 3. Fit indices from the invariance tests indicated that all of the paths between the global latent EC factor and each of the problem behavior factors were invariant between boys and girls, providing general support for a similar model of problem behavior across sexes. As an exception, tests for scalar invariance showed that the indicator intercepts for the Emotional Dysregulation Behavior Factor were different for boys and girls. Specifically, this analysis revealed that the estimated indicator mean for the CBQ Anger/Frustration scale was higher for girls. In addition, the correlation between the Attention Problems and Emotional Dysregulation Behavior factors was lower in girls compared to boys. Finally, there was some heterogeneity in the degree of association between age and each of the latent factors across sexes. While associations between age and Attention Problems, as well as age and Disinhibition Behaviors, were invariant across girls and boys, associations between age and Hyperactive Behaviors, Emotional Dysregulation, and $\mathrm{EC}$ were not equivalent. 


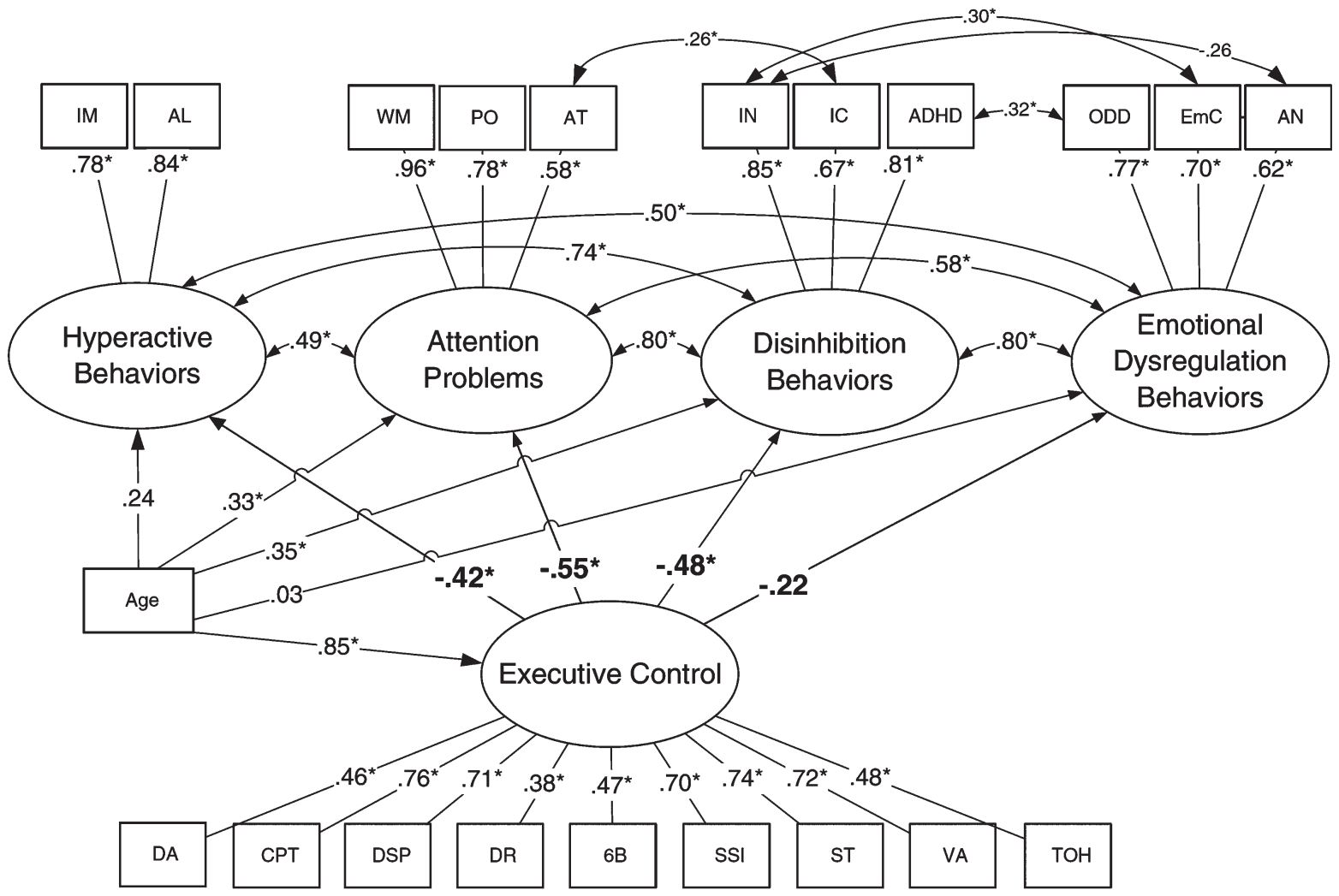

Figure 3. Problem behavior-executive control model for girls and boys. Standardized factor loadings and coefficients are reported. Model paths allowed to vary between girls and boys are denoted with dashed lines. IM = CBQ Impulsivity; $A L=C B Q$ Activity Level; WM = BRIEF-P Working Memory; PO = BRIEF-P Plan/Organize; AT = CBQ Attentional Focusing; IN = BRIEF-P Inhibit; $\mathrm{IC}=\mathrm{CBQ}$ Inhibitory Control; ADHD = CBCL Attention Deficit/Hyperactivity Problems; ODD = CBCL Oppositional Defiant Problems; EmC = BRIEF-P Emotional Control; AN = CBQ Anger/Frustration; DA = Delayed Alternation; CPT = Continuous Performance Test; DSP = DAS Digit Span; DR = Delayed Response; 6B = Six Boxes; SSI = Shape School Inhibit condition; ST = NEPSY Statue; VA = NEPSY Visual Attention; TOH = Tower of Hanoi. Slight differences in model standard errors can cause factor loadings to appear different although they are actually invariant for girls and boys

\section{Discussion}

First, problem behavior manifested in the child's realworld setting, as observed and evaluated by a parent informant, was parsed into 4 distinct, yet interrelated, constructs using confirmatory factor analysis, namely, Hyperactive Behaviors, Attention Problems, Disinhibition Behaviors, and Emotional Dysregulation Behaviors. Importantly, these four constructs were apparent after integrating informant ratings across developmentally and clinically oriented measures, which yielded a more nuanced, multidimensional structure than typically has been observed with either of these approaches alone (e.g., Rothbart et al., 2001; Achenbach \& Rescorla, 2000). This model of behavioral control is consistent with a strong theoretical and research base suggesting subtle distinctions among these various aspects of behavior (e.g., Carlson \& Wang, 2007; Kieling et al., 2008). Based on this dimensional approach, there were strong, significant relations between latent EC and Hyperactive Behaviors, Attention Problems, and Disinhibition Behaviors, and when sex-specific relations were allowed, a trend $(p=.05)$ between EC and Emotional Dysregulation Behaviors in boys and girls. Furthermore, when the influence of the child's estimated intelligence was covaried with EC, the relations to problem behavior were robust. Finally, parents' age-based expectations regarding problem behaviors were more prominent for Attention Problems and Disinhibition Behaviors than for Hyperactivity or Emotional Dyregulation Behaviors.

As hypothesized, EC defined systematically by the shared variance from directly administered, laboratory executive tasks was related to empirically derived latent dimensions of problem behaviors in preschoolers. The latent variable approach that capitalizes on common variance among executive measures yielded substantially stronger relations than have been observed previously when EC has been measured by single laboratory tests (Olson et al., 2005; Thorell \& Wåhlstedt, 2006) or by a summed common index (Cole, Usher, \& Cargo, 1993; Hughes \& Ensor, 2008; Sonuga-Barke et al., 2003). Isolating the salient common variance across tasks and across behavior scales likely improved specificity and reduced extraneous variance. Because pre- 
school children's thoughts, responses, and behaviors can be idiosyncratic, thereby adding extraneous variability, these methods may be particularly useful in young age ranges.

Using two levels of analysis, EC processes that are manifest under experimentally manipulated conditions in the laboratory were strongly and independently related to a spectrum of problem behaviors that the child expresses in the real-world environment observed by parents. Wiebe et al.'s (2008) unitary factor model representing preschool executive task performance is consistent with neural-level findings of fluid, task-dependent prefrontal activation patterns (e.g., Miller \& Cohen, 2001; Knight, 2007). In these models, the fundamental role of the prefrontal system is modulatory, exerting top-down control by biasing activity in task-relevant neural pathways, where observed behavior is a function of the relative strength of the pathways supporting the task-relevant process compared to those pathways carrying competing 'bottom-up' information (e.g., distracters; Buschman \& Miller, 2007). These core neural processes are engaged in a wide range of contexts, including controlled laboratory executive tasks, as well as naturalistic home or school settings captured by informant ratings. For example, when a preschool child plays a board game with siblings, she must direct her attention purposely to the dice and intentionally move her game piece only the allotted number of spaces, suppressing her desire to move closer to the winning spot. She also must adapt her responses flexibly when a peer allots the 'skip turn' to her, control her anger, and wait until her next turn to proceed with the game, in order to adaptively participate as a player. These regulatory demands can be considered omnipresent but manifested in context-specific forms unique to the laboratory testing, social, home, or academic settings, and yet similarly invoke executive control to enable goal-directed action, thought and behavior that ultimately support social and academic competence (e.g., Blair \& Razza, 2007; Dennis, Brotman, Huang, \& Gouley, 2007).

The marginal relations between latent EC and Emotional Dysregulation Behaviors, characterized by poor modulatory management of negative emotionality such as anger, aggressive behavior, and non-compliance, merit further comment. These results are consistent with a) recent evidence that control of cognition and emotion information are related (Carstensen, Fung, \& Charles, 2003; Gross, 2002; Leerkes et al., 2008), b) the neuroanatomical patterns of prefrontal connectivity as the nexus of the limbic and attention systems (e.g., Middleton \& Strick, 2002; Pandya \& Yeterian, 1996), c) the emerging evidence of interactions among executive and emotional task demands (e.g., Zelazo \& Cunningham, 2007; Carlson \& Wang, 2007), and d) differences in executive task performance among children with disruptive behavioral problems (Oosterlaan et al., 1998; Séguin et al., 2004). Importantly, allowing sex-specific models revealed somewhat different patterns of interrelation for the Attention Problems and Emotional Dysregulatory Behaviors latents. Preschool girls had higher scores on the CBQ Anger/Frustration scale. The sex-dependent difference in standardized correlation between the Attention Problems and Emotional Dysregulatory Behaviors latents indicates that for girls, inattention and emotional regulation problems are more independent of each other (Hinshaw, Owens, Sami, \& Fargeon, 2006; Mahone \& Wodka, 2008), compared to boys.

In this sample of typically developing preschoolers, EC measured by laboratory tasks appears to tap abilities that support broad control processes that enable behavioral regulation across cognitive and emotional domains. Indeed, if the paths from EC to the four Problem Behavior latents are constrained to be equal, there is no difference in model fit from the final model where the paths are estimated freely (all $\lambda^{\prime} \mathrm{s}=-.42, p<.05$; $\chi^{2} \Delta=.61$, CFI $=.961$, RMSEA $=.042 ;$ BIC $\left.=9764\right)$, supporting this view. Clinically, these results imply that EC tasks administered in the laboratory are good markers for broad regulatory competency of the preschool child as perceived by the parent, even for preschoolers who are not clinically diagnosed. However, substantial power was gained by empirically 'pooling' across EC measures, substantiating the remaining need for considerable measurement work before any single task is suitable for use to predict problem behavior at the level of the individual preschool child. High correlations between latent behavioral constructs also reflect the multifaceted nature of behavioral difficulties and are consistent with high rates of comorbidity seen in childhood behavioral disorders. Nonetheless, the pooling of behavioral measures from the differing assessment traditions also provided greater leverage in isolating the more difficult-to-discriminate dimensions of problem behavior (i.e., difficulties in appropriately directing and sustaining attention) that do not manifest as heightened activity level or aggression, but that are also likely to cause increasing difficulties as children move into formal schooling. In keeping with recent research (Bierman et al., 2008), the model suggests that early interventions aimed at improving early executive abilities are likely to have widespread effects across problem behavior domains. Also of relevance for research and clinical practice is the finding that scales from the BRIEF-P could not be parsed empirically from those of the CBCL or CBQ using structural equation methods, the correlations between scales generally being robust and consistent across these outcome measures. Based on our results, the BRIEF-P should best be utilized as a broad indicator of problem behavior within everyday contexts, as opposed to a substitute for direct, examiner-administered assessment of child executive skills. 
Although problem behavior was measured carefully by informant reports on multiple scales, patterns of findings might differ for behavior observed in vivo in the home or school setting, as informant ratings require evaluative judgments that depend in part on maternal characteristics and internal normative expectations that are not always accurate, and certainly vary across informants. Parents of typically developing preschoolers are less likely to view disruptive behaviors as norm-violating in this young age range, and thus may under-endorse questionnaire items (Wakschlag \& Hans, 2002), consistent with the present findings. Although children varied in problem behavior, clinically diagnosed preschoolers were not sampled, and thus the observed relations to EC may have been somewhat attenuated. Also, the shared variance captured by the EC factor may reflect another unidentified construct common to these tasks, although this possibility was addressed empirically in Wiebe et al.'s (2009) original analysis comparing the fit of models parsed on the basis of speeded performance, as well as verbal and spatial demands. Despite these potential limitations, the present findings delineating a strong, systematic relation between EC and problem behavior in typically developing preschool children provide a platform for future efforts to more fully specify the role of EC in the developmental pathways as they unfold dynamically across this critical period.

\section{Key points}

- Although there is consensus that executive control plays an important role in externalizing psychopathology, the relation to problem behavior in non-referred, community based preschoolers is unclear.

- Sophisticated structural modeling techniques removed extraneous variance and empirically identified four distinct, yet interrelated, problem behavior constructs that were related strongly and robustly to preschool executive control.

- Application of latent variable methods enhanced the characterization of problem behaviors and revealed that executive control measured by laboratory tasks appears to tap abilities that support broad control processes enabling behavioral regulation across cognitive and emotional domains.

Acknowledgments - This research was supported in part by National Institutes of Health grants R01 MH065668, DA014661, DA023653, HD050309, and P01 HD038051. The authors acknowledge the participating families and project personnel who made this work possible.

\section{References}

Achenbach, T., \& Rescorla, L. (2000). Manual for the ASEBA preschool forms and profiles. Burlington, VT: University of Vermont.

Barkley, R. (1997). Behavioral inhibition, sustained attention, and executive functions: Constructing a unifying theory of ADHD. Psychological Bulletin, 121, 65-94.

Bell, M., \& Deater-Deckard, K. (2007). Biological systems and the development of self-regulation: Integrating behavior, genetics, and psychophysiology. Journal of Developmental and Behavioral Pediatrics, 28, 409-420.

Bell, M.A., \& Fox, N. (1992). The relations between frontal brain electrical activity and cognitive development during infancy. Child Development, 63, 1142-1163.

Benes, F. (2001). The development of prefrontal cortex: The maturation of neurotransmitter systems and their interactions. In C. Nelson, \& M. Luciana, (Eds), Handbook of developmental cognitive neuroscience (pp. 79-105). Cambridge, MA: MIT Press.

Berlin, L., Bohlin, G., \& Rydell, A.-M. (2003). Relations between inhibition, executive functioning, and ADHD symptoms: A longitudinal study from age 5 to $81 / 2$ years. Child Neuropsychology, 9, 255-266.

Berwid, O., Kera, E., Marks, D., Santra, A., Bender, H., \& Halperin, J. (2005). Sustained attention and response inhibition in young children at risk for attention deficit/ hyperactivity disorder. Journal of Child Psychology and Psychiatry, 46, 12191229.

Bierman, K.L., Nix, R.L., Greenberg, M.T., Blair, C., \& Domitrovich, C.E. (2008). Executive functions and school readiness intervention: Impact, moderation, and mediation in the Head Start REDI program. Development and Psychopathology, 20, 821-843.

Blair, C. (2003). Behavioral inhibition and behavioral activation in young children: Relations with self-regulation and adaptation to preschool in children attending head start. Developmental Psychobiology, 42, 301-311.

Blair, C., \& Razza, R. (2007). Relating effortful control, executive function, and false belief understanding to emerging math and literacy ability in kindergarten. Child Development, 78, 647-663.

Bollen, K. (1989). Structural equations with latent variables. New York: Wiley.

Brocki, K.C., Nyberg, L., Thorell, L.B., \& Bohlin, G. (2007). Early concurrent and longitudinal symptoms of ADHD and ODD: Relations to different types of inhibitory control and working memory. Journal of Child Psychology and Psychiatry, 48, 1033-1041.

Bull, R., Espy, K.A., \& Senn, T.E. (2004). A comparison of performance on the Towers of London and Hanoi in young children. Journal of Child Psychology and Psychiatry, 45, 734-754.

Buschman, T., \& Miller, E. (2007). Top-down versus bottom-up control of attention in the prefrontal and posterior parietal cortices. Science, 315, 1860-1862.

Campbell, S.B. (1982). A multidimensional assessment of parent-identified behavior problem toddlers. Journal of Abnormal Child Psychology, 10, 569-591. 
Carlson, S., \& Wang, T. (2007). Inhibitory control and emotional regulation in preschool children. Cognitive Development, 22, 489-510.

Carlson, S.M. (2005). Developmentally sensitive measures of executive function in preschool children. Developmental Neuropsychology, 28, 596-616.

Carstensen, L., Fung, H., \& Charles, S. (2003). Socioemotional selectivity theory and the regulation of emotion in the second half of life. Motivation and Emotion, 27, 103- 123.

Casey, B.J. (2000). Structural and functional brain development and its relation to cognitive development. Biological Psychiatry, 54, 241-257.

Castellanos, F.X., Sonuga-Barke, E., Milham, M., \& Tannock, R. (2006). Characterizing cognition in ADHD: Beyond executive dysfunction. Trends in Cognitive Science, 10, 117-123.

Chang, F., \& Burns, B. (2005). Attention in preschoolers: Associations with effortful control and motivation. Child Development, 76, 247-263.

Cole, P., Usher, B.A., \& Cargo, A.P. (1993). Cognitive risk and its association with risk for disruptive behavior in preschoolers. Journal of Clinical Child Psychology, 22, 154-164.

Dennis, T., Brotman, L., Huang, K., \& Gouley, K. (2007). Effortful control, social competence, and adjustment problems in children at risk for psychopathology. Journal of Clinical Child and Adolescent Psychology, 36, 442-454.

Diamond, A., Diamond, A., Prevor, M.B., Callender, G., \& Druin, D.P. (1997). Prefrontal cortex cognitive deficits in children treated early and continuously for PKU. Monographs of the Society for Research in Child Development, 62, 1.

Dunn, J., \& Hughes, C. (2001). 'I got some swords and you're dead!': Violent fantasy, antisocial behavior, friendship, and moral sensibility in young children. Child Development, 72, 491-505.

Dunn, L., \& Dunn, L. (1997). Peabody Picture Vocabulary Test Third Edition (PPVT-III). Circle Pines, MN: AGS.

Durston, S., \& Casey, B.J. (2006). What have we learned about cognitive development from neuroimaging? Neuropsychologia, 44, 2149-2157.

Egger, H., Kondo, D., \& Angold, A. (2006). The epidemiology and diagnostic issues in preschool attention-deficit/ hyperactivity disorder: A review. Infants and Young Children, 19, 109-122.

Elliott, C.D. (1990). Differential Ability Scales. San Antonio, TX: The Psychological Corporation.

Eisenberg, N., Cumberland, A., Spinrad, T., Fabes, R., Shepherd, S., Reiser, M., Murphy, B., Losoya, S., \& Guthrie, I. (2001). The relations of regulation and emotionality to children's internalizing and externalizing problem behaviors. Child Development, 72, 1114-1132.

Eisenberg, N., Valiente, C., Spinrad, T.L., Liew, J., Zhou, Q., Losoya, S.H., et al. (2009). Longitudinal relations of children's effortful control, impulsivity, and negative emotionality to their externalizing, internalizing and cooccurring behavior problems. Developmental Psychology, 45, 988-1008.

Espy, K.A. (1997). The Shape School: Assessing executive function in preschool children. Developmental Neuropsychology, 13, 495-499.
Espy, K.A. (2004). Using developmental, cognitive, and neuroscience approaches to understand executive control in young children. Developmental Neuropsychology, 26, 379-384.

Espy, K.A., Bull, R., Martin, J., \& Stroup, W. (2006). Measuring the development of executive control with the Shape School. Psychological Assessment, 18, 373- 381.

Espy, K.A., Kaufman, P.M., \& Glisky, M.L. (1999). Neuropsychologic function in toddlers exposed to cocaine in utero: A preliminary study. Developmental Neuropsychology, 15, 447-465.

Fair, D.A., Cohen, A.L., Dosenbach, N.U., Church, J.A., Miezin, F.M., Barch, D.M., Raichle, M.E., Peterson, S.E., \& Schlaggar, B.L. (2008). The maturing architecture of the brain's default network. PNAS, 105, 4028-4032.

Friedman, N.P., Haberstick, B.C., Willcutt, E.G., Miyake, A., Young, S.E., Corley, R.P., \& Hewitt, J.K. (2007). Greater attention problems during childhood predict poorer executive functioning in late adolescence. Psychological Science, 18, 893 900.

Gerardi-Caulton, G. (2000). Sensitivity to spatial conflict and the development of self-regulation in children 24-36 months of age. Developmental Science, 3, 397-404.

Giedd, J., Blumenthal, J., Jeffries, N., Rajapakse, J., Vaituzis, A., Liu, H., Berry, Y., Tobin, M., Nelson, J., \& Castellanos, F. (1999). Development of the human corpus callosum during childhood and adolescence: A longitudinal MRI study. Progress in Neuro-Psychopharmacology and Biological Psychiatry, 23, 571-588.

Gioia, G., Espy, K.A., \& Isquith, P. (2003). Behavior Rating Inventory of Executive Function - Preschool Version (BRIEF-P). Lutz, FL: Psychological Assessment Resources.

Goldman, P.S., Rosvold, H.E., \& Mishkin, M. (1970). Evidence for behavioral impairment following prefrontal lobectomy in the infant monkey. Journal of Comparative and Physiological Psychology, 70, 454.

Goldman, P.S., Rosvold, H.E., Vest, B., \& Galkin, T.W. (1971). Analysis of the delayed alternation deficit produced by dorsolateral prefrontal lesions in the rhesus monkey. Journal of Comparative and Physiological Psychology, 77, 212-220.

Goodman, R. (1997). The Strengths and Difficulties Questionnaire: A research note. Journal of Child Psychology and Psychiatry, 38, 581-586.

Gross, J. (2002). Emotion regulation: Affective, cognitive, and social consequences. Psychophysiology, 39, 281- 291.

Hinshaw, S.P., Owens, E., Sami, N., \& Fargeon, S. (2006). Prospective follow-up of girls with attention deficit/ hyperactivity disorder into adolescence: Evidence for continuing cross-domain impairment. Journal of Consulting and Clinical Psychology, 74, 489-499.

Hu, L., \& Bentler, P. (1999). Cutoff criteria for fit indices in covariance structure analysis: Conventional criteria versus new alternatives. Structural Equation Modeling, 6, 1-55.

Hughes, C., Dunn, J., \& White, A. (1998). Trick or treat? Uneven understanding of mind and emotion and executive dysfunction in 'hard-to-manage' preschoolers Journal of Child Psychology and Psychiatry, 39, 981- 994.

Hughes, C., \& Ensor, R. (2008). Does executive function matter for preschoolers' problem behaviors? Journal of Abnormal Child Psychology, 36, 1-14. 
Hughes, C., Ensor, R., Wilson, A., \& Graham, A. (2010). Tracking executive function across the transition to school: A latent variable approach. Developmental Neuropsychology, 35, 20-36.

Hughes, C., White, A., Sharpen, J., \& Dunn, J. (2000). Antisocial, angry, and unsympathetic: 'Hard-to-manage' preschoolers' peer problems and possible cognitive influences. Journal of Child Psychology and Psychiatry, 41, 169-179.

Huizinga, M., Dolan, C.V., \& van der Molan, M.W. (2006). Age-related changes in executive function: Developmental trends and a latent variable analysis. Neuropsychologia, 44, 2017-2036.

Huttenlocher, P. (1990). Morphometric study of human cerebral cortex development. Neuropsychologia, 28, 117- 128.

Isquith, P., Gioia, G., \& Espy, K. A. (2004). Executive function in preschool children: Examination through everyday behavior. Developmental Neuropsychology, 26, 403-422.

Jo“reskog, K. (1969). A general approach to confirmatory factor analysis. Psychometrika, 34, 183-202.

Karmiloff-Smith, A. (2007). Atypical epigenesis. Developmental Science, 10, 84-88.

Karreman, A., van Tuijl, C., van Aken, M.A.G.,\&Dekovic, M. (2009). Predicting young children's externalizing problems: Interactions among effortful control, parenting, and child gender. Merrill-Palmer Quarterly, 55, 111-134.

Keenan, K., Wakschlag, L., Danis, B., Hill, C., Humphries, M., Duax, J., \& Donald, R. (2007). Further evidence of the reliability and validity of DSM-IV ODD and CD in preschool children. Journal of the American Academy of Child and Adolescent Psychiatry, 46, 457-468.

Kerns, K.A., \& Rondeau, L.A. (1998). Development of a continuous performance test for preschool children. Journal of Attention Disorders, 2, 229.

Kieling, C., Goncalves, R., Tannock, R., \& Castellanos, F.X. (2008). Neurobiology of attention deficit hyperactivity disorder. Child and Adolescent Psychiatric Clinics of North America, 17, 285-307.

Knight, R. (2007). Neural networks debunk phrenology. Science, 316, 1578-1579.

Kochanska, G., Murray, K., \& Coy, K. (1997). Inhibitory control as a contributor to conscience in childhood: From toddler to early school age. Child Development, 68, 263-277.

Kochanska, G., Murray, K., \& Harlan, E.T. (2000). Effortful control in early childhood: Continuity, change, antecedents and implications for social development. Developmental Psychology, 36, 220-232.

Korkman, M., Kirk, U., \& Kemp, S. (1998). NEPSY: A developmental neuropsychological assessment. Boston, MA: The Psychological Association.

Lahey, B., Pelham, W., Loney, J., Kipp, H., Ehrhardt, A., Less, S., Willcutt, E., Hartung, C., Chronis, A., \& Massetti, G. (2004). Three-year predictive validity of DSM-IV attention deficit hyperactivity disorder in children diagnosed at 4-6 years of age. American Journal of Psychiatry, 161, 2014-2020.

Landau, S., Milich, R., \& Widiger, T.A. (1991). Conditional probabilities of child interview symptoms in the diagnosis of attention deficit disorder. Journal of Child Psychology and Psychiatry, 32, 501-513.
Lavigne, J., Arend, R., Rosenbaum, D., Binns, H., Christoffell, K., \& Gibbons, R. (1998a). Psychiatric disorders with onset in the preschool years: I. Stability of diagnoses. Journal of the American Academy of Child and Adolescent Psychiatry, 37, $1255-1261$.

Lavigne, J., Arend, R., Rosenbaum, D., Binns, H., Christoffell, K., \& Gibbons, R. (1998b). Psychiatric disorders with onset in the preschool years: II. Correlates and predictors of stable case status. Journal of the American Academy of Child and Adolescent Psychiatry, 37, 1246-1254.

Leerkes, E., Paradise, M., O’Brien, M., Calkins, S., \& Lange, G. (2008). Emotion and cognition processes in preschool children. Merrill-Palmer Quarterly, 54, 102- 124.

Lehto, J. E., Juujarvi, P., Kooistra, L., \& Pulkkinen, L. (2003). Dimensions of executive functioning: Evidence from children. British Journal of Developmental Psychology, 21, 59-70.

Mahone, E.M., \& Wodka, E.L. (2008). The neurobiological profile of girls with ADHD. Developmental Disabilities Research Reviews, 14, 276-284.

Martel, M.M. (2009). Research Review: A new perspective on attention deficit/hyperactivity disorder: Emotion dysregulation and trait methods. Journal of Child Psychology and Psychiatry, 50, 1042-1051.

Martinussen, R., Hayden, J., Hogg-Johnson, S., \& Tannock, R. (2005). A meta-analysis of working memory impairments in children with attention-deficit/hyperactivity disorder. Journal of the American Academy of Child and Adolescent Psychiatry, 44, 377-384.

Middleton, F., \& Strick, P. (2002). Basal-ganglia 'projections' to the prefrontal cortex of the primate. Cerebral Cortex, 12, 926935.

Miller, E., \& Cohen, J. (2001). An integrative theory of prefrontal cortex function. Annual Reviews of Neuroscience, 24, 167202.

Miyake, A., Friedman, N.P., Emerson, M.J., Witzki, A.H., Howerter, A., \& Wager, T.D. (2000). The unity and diversity of executive functions and their contributions to complex, 'frontal lobe' tasks: A latent variable analysis. Cognitive Psychology, 41, 49-100.

Muthe'n, L., \& Muthe'n, B. (2006). Mplus user's guide (4th edn). Los Angeles, CA: Muthe'n \& Muthe'n.

Nigg, J., \& Casey, B.J. (2005). An integrative theory of attention-deficit/hyperactivity disorder based on the cognitive and affective neurosciences. Developmental Psychopathology, $17,785-806$.

Nigg, J., Goldsmith, H., \& Sachek, J. (2004). Temperament and attention deficit hyperactivity disorder: The development of a multiple pathway model. Journal of Clinical Child and Adolescent Psychology, 33, 42-53.

Nigg, J., \& Huang-Pollock, C. (2003). An early-onset model of the role of executive functions and intelligence in conduct disorder/delinquency. In B. Lahey, T. Moffitt, \& A. Caspi, (Eds), Causes of conduct disorder and juvenile delinquency (pp. 227-253). New York: Guilford Press.

Olson, S.L., Sameroff, A., Kerr, D.C.R., Lopez, N.L., \& Wellman, H.M. (2005). Developmental foundations of externalizing problems in young children: The role of effortful control. Development and Psychopathology, 17, 25-45. 
Oosterlaan, J., Logan, G., \& Sergeant, J. (1998). Response inhibition in $\mathrm{AD} / \mathrm{HD}, \mathrm{CD}$, comorbid $\mathrm{AD} / \mathrm{HD}+\mathrm{CD}$, anxious, and control children: A meta-analysis of studies with the stop task. Journal of Child Psychology and Psychiatry, 39, 411425.

Pandya, D., \& Yeterian, E. (1996). Morphological correlations of human and monkey frontal lobes. In A. Damasio, H. Damasio, \& Y. Christen, (Eds), Neurobiology of decision making (pp. 13-46). New York: Springer-Verlag.

Raaijmakers, M.A.J., Smidts, D.P., Sergeant, J.A., Maassen, G.H., Posthumus, J.A., van Engeland, H., et al. (2008). Executive functions in preschool children with aggressive behavior: Impairments in inhibitory control. Journal of Abnormal Child Psychology, 36, 1097-1107.

Raftery, A. (1993). Bayesian model selection in structural equation models. In K. Bollen, \& J. Long, (Eds), Testing structural equation models (pp. 163-180). Thousand Oaks, CA: Sage.

Rothbart, M., Ahadi, S., Hersey, K., \& Fisher, P. (2001). Investigations of temperament at three to seven years: The Children's Behavior Questionnaire. Child Development, 72, 13941408.

Rothbart, M., Ellis, L., Rueda, M., \& Posner, M. (2003). Developing mechanisms of temperamental effortful control. Journal of Personality, 71, 1113-1143.

Ruff, H.A., \& Rothbart, M.K. (1996). Attention in early development: Themes and variations. New York: Oxford University Press.

Séguin, J., Nagin, D., \& Assaad, J. (2004). Cognitiveneuropsychological function in chronic physical aggression and hyperactivity. Journal of Abnormal Psychology, 113, 603-613.

Simon, H.A. (1975). The functional equivalence of problem solving skills. Cognitive Psychology, 7, 268.

Snowling, M. (2009). Multiple perspectives on ADHD: Implications for future research. Journal of Child Psychology and Psychiatry, 50, 1039-1041.

Sonuga-Barke, E. (2005). Causal models of attentiondeficit/ hyperactivity disorder: From common simple deficits to multiple developmental pathways. Biological Psychiatry, 57, 1231-1238.

Sonuga-Barke, E.J.S., Dalen, L., Daley, D., \& Remington, B. (2002). Are planning, working memory, and inhibition associated with individual differences in preschool ADHD symptoms? Developmental Neuropsychology, 21, 255-272.

Sonuga-Barke, E.J.S., Dalen, L., \& Remington, B. (2003). Do executive deficits and delay aversion make independent contributions to preschool attention-deficit/hyperactivity disorder symptoms? Journal of the American Academy of Child andE Adolescent Psychiatry, 42, 1335-1342.

Spira, E., \& Fischel, J. (2005). The impact of preschool inattention, hyperactivity, and impulsivity on social and academic development: A review. Journal of Child Psychology and Psychiatry, 46, 755-773.

Thatcher, R. (1991). Maturation of the human frontal lobes: Physiological evidence for staging. Developmental Neuropsychology, 7, 397-419.
Thatcher, R.W. (1997). Neural coherence and the content of consciousness. Consciousness and Cognition: An International Journal, 6, 42-49.

Thorell, L., \& $\mathrm{Wa}^{\circ}$ hlstedt, C. (2006). Executive functioning deficits in relation to symptoms of ADHD and/or ODD in preschool children. Infant and Child Development, 15, 503518.

van der Sluis, S., de Jong, P., \& van der Leij, A. (2007). Executive functioning in children and its relations with reasoning, reading and arithmetic. Intelligence, 35, 427- 449.

Wakschlag, L., Briggs-Gowan, M., Carter, A., Hill, C., Danis, B., Keenan, K., McCarthy, K., \& Leventhal, B. (2007). A developmental framework for distinguishing disruptive behavior from normative misbehavior in preschool children. Journal of Child Psychology and Psychiatry, 48, 976-987.

Wakschlag, L., \& Hans, S. (2002). Maternal smoking during pregnancy and conduct problems in high-risk youth: A developmental framework. Development and Psychopathology, 14, 351-369.

Wakschlag, L., Leventhal, B., Pine, D., Pickett, K., \& Carter, A. (2006). Elucidating early mechanisms of developmental psychopathology: The case of prenatal smoking and disruptive behavior. Child Development, 77, 893-906.

Welsh, M.C., Pennington, B.F., \& Groisser, D.B. (1991). A normative developmental study of executive function: A window on prefrontal function in children. Developmental Neuropsychology, 7, 131-149.

Wiebe, S., Espy, K.A., \& Charak, D. (2008). Using confirmatory factor analysis to understand executive control in preschool children: I. Latent structure. Developmental Psychology, 44, 575-587.

Wiebe, S.A., Clark, C.A.C., Chevalier, N., Sheffield, T., Nelson, J.,\&Espy, K.A. (2009). Determining the structure of executive control in 3-year-old children: Further evidence for unity. Manuscript under review for publication.

Willcutt, E., Doyle, A., Nigg, J., Faraone, S., \& Pennington, B. (2005). Validity of the executive function theory of attention-deficit/hyperactivity disorder: A meta-analytic review. Biological Psychiatry, 57, 1336-1346.

Youngwirth, S.D., Harvey, E.A., Gates, E.C., Hashim, R.L., \& Friedman-Weieneth, J.L. (2007). Neuropsychological abilities of preschool-aged children who display hyperactivity and/or oppositional-defiant behavior problems. Child Neuropsychology, 13, 422-443.

Yu, C. (2002). Evaluating cutoff criteria of model fit indices for latent variable models with binary and continuous outcomes. Unpublished doctoral dissertation, University of California at Los Angeles.

Zelazo, P.D., \& Cunningham, W. (2007). Executive function: Mechanisms underlying emotion regulation. In J. Gross, (Ed), Handbook of emotion regulation (pp. 135- 158). New York: Guilford Press. 